\title{
The 2014 Survey on Living with Chronic Diseases in Canada on Mood and Anxiety Disorders: a methodological overview
}

\author{
S. O'Donnell, MSc (1); R. Cheung, PhD (1); K. Bennett, PhD (2); C. Lagacé, MSc (1)
}

This article has been peer reviewed.

Tweet this article

\begin{abstract}
Introduction: There is a paucity of information about the impact of mood and anxiety disorders on Canadians and the approaches used to manage them. To address this gap, the 2014 Survey on Living with Chronic Diseases in Canada-Mood and Anxiety Disorders Component (SLCDC-MA) was developed. The purpose of this paper is to describe the methodology of the 2014 SLCDC-MA and examine the sociodemographic characteristics of the final sample.

Methods: The 2014 SLCDC-MA is a cross-sectional follow-up survey that includes Canadians from the 10 provinces aged 18 years and older with mood and/or anxiety disorders diagnosed by a health professional that are expected to last, or have already lasted, six months or more. The survey was developed by the Public Health Agency of Canada (PHAC) through an iterative, consultative process with Statistics Canada and external experts. Statistics Canada performed content testing, designed the sampling frame and strategies and collected and processed the data. PHAC used descriptive analyses to describe the respondents' sociodemographic characteristics, produced nationally representative estimates using survey weights provided by Statistics Canada, and generated variance estimates using bootstrap methodology.
\end{abstract}

Results: The final 2014 SLCDC-MA sample consists of a total of 3361 respondents (68.9\% response rate). Among Canadian adults with mood and/or anxiety disorders, close to twothirds $(64 \%)$ were female, over half $(56 \%)$ were married/in a common-law relationship and $60 \%$ obtained a post-secondary education. Most were young or middle-aged $(85 \%)$, Canadian born (88\%), of non-Aboriginal status $(95 \%)$, and resided in an urban setting $(82 \%)$. Household income was fairly evenly distributed between the adequacy quintiles; however, individuals were more likely to report a household income adequacy within the lowest $(23 \%)$ versus highest $(17 \%)$ quintile. Forty-five percent reported having a mood disorder only, $24 \%$ an anxiety disorder only and $31 \%$ both kinds of disorder.

Conclusion: The 2014 SLCDC-MA is the only national household survey to collect information on the experiences of Canadians living with a professionally diagnosed mood and/or anxiety disorder. The information collected offers insights into areas where additional support or interventions may be needed and provides baseline information for future public health research in the area of mental illness.

Keywords: mood disorders, anxiety disorders, mental health impacts, disease management, survey methodology, health surveys, population surveillance, Survey on Living with Chronic Diseases in Canada

\section{Introduction}

Mood and anxiety disorders are the most common mental health problems affecting Canadians. ${ }^{1}$ In 2013, an estimated 3 million people (11.6\%) aged 18 years or older reported having one or both types of disorder. $^{2}$ Mood disorders are characterized by the lowering or elevation of a person's mood and include depressive and bipolar disorders. Anxiety disorders are characterized by excessive and persistent feelings

\section{Highlights}

- The 2014 Survey on Living with Chronic Diseases in Canada-Mood and Anxiety Disorders Component (SLCDC-MA) is the only populationbased household survey to date that has collected information on the experiences of Canadians living with professionally diagnosed mood and/ or anxiety disorders.

- A total of 3361 respondents $(68.9 \%$ response rate) completed the survey, which covered a broad range of topics including diagnosis, impacts on usual and work-related activities, stress, sleep, social relationships, health professional contacts and recommendations, medication use, counselling and self-management practices.

- The information collected provides insights into areas where additional support or interventions may be needed. Survey findings also provide baseline information for future public health research in the area of mental illness.

of worry and fear and include generalized anxiety disorder, specific phobias, social anxiety disorder, agoraphobia, obsessivecompulsive disorder, panic disorder and posttraumatic stress disorder. ${ }^{3}$ Mood and anxiety disorders often co-occur ${ }^{4-9}$ and their co-occurrence with other mental disorders (such as substance abuse disorder and impulse control disorder) is also common. ${ }^{9-11}$

The impairments associated with mood and anxiety disorders can be profound, interfering with activities of daily living and the ability to maintain employment, 
and disrupting relationships with friends and family. ${ }^{3}$ Fortunately, professional care combined with active engagement in selfmanagement strategies can reduce the impact of these disorders and improve the well-being of those affected. ${ }^{12}$ However, many challenges remain regarding access to and receipt of effective treatments. ${ }^{13} \mathrm{~A}$ large proportion of people with these disorders fails to seek care and remains undiagnosed. Among those who do seek care, it has been documented worldwide that a substantial proportion receives suboptimal treatment or no treatment at all. ${ }^{14-17}$ Lack of knowledge, attitudes and/or beliefs and fear of the stigma of mental illness and its treatment are among the more commonly cited barriers to seeking care, while practical barriers such as time constraints, costs and access to mental health services are less frequently reported. ${ }^{18,19}$

At present, there is a lack of up-to-date information on the experiences of Canadians living with mood and/or anxiety disorders, and more specifically, the impact these disorders have on Canadians' usual and work-related activities and the approaches used to manage them. To address these gaps, the Public Health Agency of Canada (PHAC), in conjunction with Statistics Canada, conducted the 2014 Survey on Living with Chronic Diseases in Canada-Mood and Anxiety Disorders Component (SLCDC-MA). ${ }^{20}$

PHAC initiated the development of the SLCDC in 2006, as there was a lack of information directly attributable to particular chronic diseases or conditions. Specific data gaps identified included symptom control, health education, selfmanagement, clinical care, prevention interventions and factors related to adherence and health behaviours. Between 2009 and 2011, the SLCDC collected data on hypertension, arthritis, chronic respiratory conditions and diabetes and, in 2014, it focussed on mood and anxiety disorders. These diseases and conditions were selected on the basis of their prevalence, their importance to public health and the priority surveillance work being done by PHAC.

As an introduction to a collection of original articles reporting on different aspects of Canadians' experiences living with a mood and/or an anxiety disorder using the 2014 SLCDC-MA, this article describes the survey objectives and methodology and examines the characteristics of the final sample.

\section{Methods}

The 2014 SLCDC-MA, a cross-sectional follow-up survey to the 2013 Canadian Community Health Survey (CCHS)Annual Component, includes Canadians 18 years and older with self-reported, professionally diagnosed mood and/or anxiety disorders. ${ }^{21}$ The CCHS, a cross-sectional annual survey, collects information related to various aspects of health in the Canadian household population including several self-reported, professionally diagnosed chronic conditions. ${ }^{22}$ Therefore, the CCHS can be used to determine the prevalence of these chronic conditions in the Canadian population. As well, it serves as the sampling frame for the SLCDC and a source of additional sociodemographic and health information since responses from the SLCDC are linked to the CCHS.

The main purpose of the 2014 SLCDC-MA was to provide detailed information on a wide variety of topics related to the experiences of Canadians living with professionally diagnosed mood and/or anxiety disorders, which is not feasible in a general population-based health survey such as the CCHS. For instance, the 2014 SLCDC-MA collected information on the impacts of respondents' mental health (e.g. disorder-attributable limitations in usual and work-related activities) and the management approaches used (e.g. medications, psychological counselling and self-management strategies). Given that the 2014 SLCDC-MA only includes people who reported having been diagnosed with a mood and/or an anxiety disorder, the estimates derived reflect the characteristics of that population, not the prevalence of the conditions.

\section{Survey objectives}

The objectives of the 2014 SLCDC-MA were to (1) assess the impact of mood and/or anxiety disorders on Canadian adults' usual and work-related activities; (2) describe how people with mood and/ or anxiety disorders manage their disorder; (3) identify the barriers to care and self-management strategies; and (4) identify factors that influence mental illness outcomes.

\section{Survey content development}

The content of the 2014 SLCDC-MA was developed through an iterative, consultative process between PHAC and Statistics Canada, with input from members of PHAC's Mental Health and Mental Illness Surveillance Advisory Committee (Advisory Committee).* Content selection was informed by the survey objectives, data gaps identified by PHAC and the Mental Health Commission of Canada (MHCC) ${ }^{12}$ as well as recommendations from the Advisory Committee.

Survey questions relevant to the domains of interest were derived from a variety of sources including publicly available population-based surveys, published instruments and/or well-known scales. Certain questions were modified based on consultations with experts and some were informed by existing national clinical practice guidelines. Questions were grouped into modules based on theme or subject matter. A description of each module, the source of the questions or instruments included, and other relevant information is summarized in Table 1.

Questions were reviewed to ensure ageand population-appropriateness, suitability for telephone administration, and relevance to the 2014 SLCDC-MA objectives. Using the 2013 CCHS questionnaire as a guide, questions were organized by theme, and reformatted focussing on sequencing and skip patterns, standardization of scales and points of view and consistent use of language. Response bias and respondent fatigue were considered when removing leading questions and potential redundancy.

Respondent burden and the time constraints of a telephone interview dictated, for the most part, the length of the survey. Content included in the questionnaire for qualitative testing was determined based on ease of analysis and interpretation, and on the potential for translating the resulting information into actionable public health messages. 
TABLE 1

Modules of the 2014 SLCDC-MA questionnaire

\begin{tabular}{|c|c|c|c|c|}
\hline Module & Content focus & $\begin{array}{l}\text { No. of } \\
\text { questions }^{\mathrm{a}}\end{array}$ & Brief description & Source \\
\hline $\begin{array}{l}\text { 1. Survey } \\
\text { introduction }\end{array}$ & Administrative & $\mathrm{n} / \mathrm{a}$ & $\begin{array}{l}\text { Provides the respondent with the necessary } \\
\text { background and purpose of the survey. }\end{array}$ & $\mathrm{n} / \mathrm{a}$ \\
\hline
\end{tabular}

$\begin{array}{lll}\text { 2. General health } \quad \text { General } & \begin{array}{l}\text { Asks respondents about their general health, } \\ \text { life satisfaction, mental health and life stress. }\end{array}\end{array}$

3. Confirmation of diagnosis

Mood or anxiety

disorder-specific $7(11)^{b}$

Confirms that the respondent belongs to the target population, and asks about the type of mood and/or anxiety disorder, the age at diagnosis and the age at first symptoms.

\section{Medication use \\ Mood or anxiety disorder-specific} $\begin{array}{ll}\text { 5. Self-management } & \begin{array}{l}\text { Mood or anxiety } \\ \text { disorder-specific }\end{array}\end{array}$
Focusses on the respondent's use of prescription medications, to help manage their mood and/or anxiety disorder, reasons for no longer taking/having never taken, adherence patterns, and the use of natural health products.

Asks respondents about things they may have done as a result of being diagnosed to help manage their mood and/or anxiety disorder, the status of their engagement at the time of survey, and reasons for not doing so. Questions are similar to those in the Clinical recommendations module in an effort to determine whether respondents are following the recommended best practices.

\begin{tabular}{|c|c|c|c|}
\hline $\begin{array}{l}\text { 6. Contact with } \\
\text { health professionals }\end{array}$ & $\begin{array}{l}\text { Mood or anxiety } \\
\text { disorder-specific }\end{array}$ & 5 & $\begin{array}{l}\text { Asks respondents about interactions with } \\
\text { health professionals regarding their mood and } \\
\text { or anxiety disorder in the past } 12 \text { months. } \\
\text { Some questions specifically ask about } \\
\text { psychological counselling. }\end{array}$ \\
\hline $\begin{array}{l}\text { 7. Clinical recommen- } \\
\text { dations }\end{array}$ & $\begin{array}{l}\text { Mood or anxiety } \\
\text { disorder-specific }\end{array}$ & 7 & $\begin{array}{l}\text { Documents specific recommendations } \\
\text { suggested by a doctor or other health } \\
\text { professional that may help respondents } \\
\text { manage their mood and/or anxiety disorder. }\end{array}$ \\
\hline $\begin{array}{l}\text { 8. Restriction of } \\
\text { activities }\end{array}$ & $\begin{array}{l}\text { Mood or anxiety } \\
\text { disorder-specific }\end{array}$ & 8 & $\begin{array}{l}\text { Asks respondents about being limited in usual } \\
\text { activities in the past } 12 \text { months because of } \\
\text { their mood and/or anxiety disorder. }\end{array}$ \\
\hline $\begin{array}{l}\text { 9. Restriction of } \\
\text { work-related activities }\end{array}$ & $\begin{array}{l}\text { Mood or anxiety } \\
\text { disorder-specific }\end{array}$ & 7 & $\begin{array}{l}\text { Asks respondents about current and past } \\
\text { employment status, and changes made to } \\
\text { work-related activities due to their mood and/ } \\
\text { or anxiety disorder. }\end{array}$ \\
\hline 10. Sleep & $\begin{array}{l}\text { Mood or anxiety } \\
\text { disorder-specific }\end{array}$ & 3 & $\begin{array}{l}\text { Asks respondents about the number of sleep } \\
\text { hours, whether they have difficulty going to } \\
\text { sleep or staying asleep and reasons why they } \\
\text { may have trouble going to sleep or staying } \\
\text { asleep. }\end{array}$ \\
\hline 11. Stress & $\begin{array}{l}\text { Mood or anxiety } \\
\text { disorder-specific }\end{array}$ & 3 & $\begin{array}{l}\text { Asks respondents about the various stressors } \\
\text { encountered in daily life, their ability to deal } \\
\text { with them, and the main source of stress. }\end{array}$ \\
\hline
\end{tabular}

Questions from the General health module of the 2013 CCHS-Annual Component ${ }^{23}$ were repeated since they serve as a good warm-up, are sensitive to change and important in the assessment of the health status of those with mood and anxiety disorders.

Modified screening questions from the Chronic conditions module of the 2013 CCHS-Annual Component ${ }^{23}$ to inquire if the respondent has, or ever has been diagnosed with a mood and/or an anxiety disorder. All other questions were adopted from a previous disease/condition-specific cycle of the SLCDC ${ }^{24}$ to capture the topics of interest in relation to mood and anxiety disorders.

Modified questions from previous disease/conditionspecific cycles of the SLCDC ${ }^{2427}$ to capture the topics of interest in relation to mood and anxiety disorders.

Modified questions from previous disease/conditionspecific cycles of the SLCDC ${ }^{24-27}$ which were informed by clinical guidelines/best practices related to self-management of mood and anxiety disorders. ${ }^{28,29}$
Modified questions from the 2013 CCHS-Annual Component ${ }^{23}$ to capture the topics of interest in relation to mood and anxiety disorders.

Modified questions from previous disease/conditionspecific cycles of the SLCDC ${ }^{24-27}$ and informed by clinical practice guidelines/best practices related to the management of mood and anxiety disorders. ${ }^{28,29}$

Modified questions from the Health status (SF-36) module in the 2013 CCHS-Annual Component ${ }^{23}$ to capture the topics of interest in relation to mood and anxiety disorders.

Modified questions from US National Health Interview Survey (NHIS). ${ }^{30}$

Questions from the Sleep module in the 2013 CCHSAnnual Component ${ }^{23}$ were repeated since they are sensitive to change. In addition, a question asking why respondents may have trouble sleeping was added.

Questions from the Stress - Sources module in the 2013 CCHS-Annual Component ${ }^{23}$ were repeated since they are sensitive to change. The question on sources of stress was modified to ensure that the response options were read to the respondent.

Continued on the following page 


\section{TABLE 1 (continued) \\ Modules of the 2014 SLCDC-MA questionnaire}

\begin{tabular}{|c|c|c|c|c|}
\hline Module & Content focus & $\begin{array}{c}\text { No. of } \\
\text { questions }^{\mathrm{a}}\end{array}$ & Brief description & Source \\
\hline $\begin{array}{l}\text { 12. Social provisions } \\
\text { scale }\end{array}$ & $\begin{array}{l}\text { Mood or anxiety } \\
\text { disorder-specific }\end{array}$ & 10 & $\begin{array}{l}\text { Focusses on the degree to which respondents' } \\
\text { social relationships provide various dimensions } \\
\text { of social support. }\end{array}$ & $\begin{array}{l}\text { Social Provisions Scale ( } 24 \text { items) developed by } \\
\text { Cutrona and Russell }(1987),{ }^{31} \text { and validated in French } \\
\text { by Caron }(1996,2013) .^{32,33}\end{array}$ \\
\hline 13. Administration & Administrative & 4 & $\begin{array}{l}\text { This module informs respondents about the } \\
\text { linking of their information from the } 2014 \\
\text { SLCDC-MA to their responses from the } 2013 \\
\text { CCHS-Annual Component. Respondents are } \\
\text { then asked if this information can be shared } \\
\text { with Statistics Canada's share partners. }\end{array}$ & 2013 CCHS-Annual Component. ${ }^{23}$ \\
\hline
\end{tabular}

Abbreviations: CCHS, Canadian Community Health Survey; n/a, not applicable; SLCDC-MA, Survey on Living with Chronic Diseases in Canada-Mood and Anxiety Component.

${ }^{a}$ The number of questions delivered to each respondent depends on skip patterns and the eligibility of the respondent for particular questions.

${ }^{\mathrm{b}}$ Although 7 questions make up this module, 2 are split into parts, resulting in a total of 11 questions.

cAlthough 9 questions make up this module, several are split into parts, resulting in a total of 22 questions.

Questions related to specific themes were removed before qualitative testing if they: (1) were already covered on the 2013 CCHS, and therefore can be obtained through record linkage (e.g. educational attainment and nutrition); (2) were too broad to be adequately addressed within the allocated survey time (e.g. health utility index, stages of behavioural change); (3) required detailed explanations; or (4) were judged to be better measured via a longitudinal survey (e.g. recovery)

Questions were added to obtain respondents' permission to share data and link their 2014 SLCDC-MA responses to those of the 2013 CCHS. The English questionnaire was translated into French to allow for implementation in the two official languages of Canada. The French translation of the questionnaire was validated in a side-by-side review. The final questionnaires were then built into a computerassisted telephone interview (CATI) application, which ensured consistent survey administration by interviewers.

\section{Qualitative testing}

Statistics Canada's Questionnaire Design and Review Centre (QDRC) tested both the English and the French 2014 SLCDC-MA questionnaires in face-to-face interviews with selected respondents.
Qualitative testing interviews were conducted in March 2013 in Toronto (English) and in Montreal (French). The 2012 CCHS-Annual Component was used as the frame to select respondents for the interviews. A total of 26 participants took part in the testing, representing a cross section of persons who reported having a mood and/or an anxiety disorder that had been diagnosed by a health professional in the 2012 CCHS interview. Informed by theoretical frameworks and methods based in cognitive and social psychology, ${ }^{34,35}$ each interview explored the four steps of the cognitive process used to respond to a questionnaire: (1) understanding the question and response categories; (2) recalling and/or searching for the requested information; (3) thinking about the answer and making a judgment about what to report; and (4) reporting the answer. All interviews were conducted by a trained interviewer from the QDRC and observed from behind a one-way mirror by members of the 2014 SLCDC-MA project team (i.e. personnel from Statistics Canada and PHAC).

The QRDC produced reports on the results of the English and French qualitative testing interviews, which were then used to further refine and finalize the survey content. Overall, the survey was well received by participants. They reported that the modules within the questionnaire flowed well and the questions within the modules covered the main aspects of living with a mood and/or an anxiety disorder. However, modules that measured the concepts of resiliency and mastery were somewhat difficult for participants to answer, due to the inclusion of questions that alternated between positive and negative concepts, and to the sensitive nature of the topics covered. In light of this difficulty, the 2014 SLCDC-MA project team decided to remove these modules from the questionnaire. Furthermore, the team made modifications to some of the retained modules in an effort to improve clarity on what was to be reported and to ensure proper identification of in-scope respondents.

\section{Final questionnaire}

The final, 20-minute questionnaire comprises 12 modules, addressing each of the objectives of the 2014 SLCDC cycle. The full questionnaire is available on Statistics Canada's website at http://www23.statcan .gc.ca/imdb/p2SV.pl?Function = getSurvey $\&$ SDDS $=5160$

\section{Targót population}

The target population of the 2014 SLCDC-MA was Canadians aged 18 years and older as of 31 December, 2013, living in private dwellings in the 10 provinces, who responded affirmatively to at least one of the following two 2013 CCHS questions: "Remember, we're interested in 
conditions diagnosed by a health professional and that are expected to last or have already lasted six months or more. Do you have a mood disorder such as depression, bipolar disorder, mania or dysthymia?" or "Do you have an anxiety disorder such as a phobia, obsessive-compulsive disorder or a panic disorder?" The study results therefore relate to Canadians who sought care for a mood or an anxiety disorder or both and received a diagnosis. Since the sample does not include Canadians who did not seek care, or who attempted to obtain care but were unsuccessful despite the presence of mood and/ or anxiety disorder symptoms that meet diagnostic criteria, the applicability of the results to these individuals is uncertain.

Residents of the three territories, people living on Indian reserves or Crown lands, people living in institutions, full-time members of the Canadian Forces and residents of certain remote regions were excluded. With the exception of the three territories, the exclusions are those of the 2013 CCHS sampling frame. Overall, these exclusions represent approximately $3 \%$ of the Canadian population.

In addition, respondents with a mood and/or an anxiety disorder living in one of the 10 provinces who met any of the following criteria were excluded from the sample:

- they did not have a valid telephone number;

- they completed the CCHS interview by proxy; and/or

- they did not give permission to share their responses with Statistics Canada share partners and to link their 2014 SLCDC-MA responses to those of the 2013 CCHS.

\section{Sampling strategy}

The survey sample was developed using a two-phase design: the first phase was the 2013 CCHS sample and the second was the 2014 SLCDC-MA sample. The 2013 CCHS sample was selected from two frames: an area frame designed for the Labour Force Survey and a list frame of telephone numbers, with each frame making up half of the sample. The 2014 SLCDC-MA sampling frame consisted of 2013 CCHS respondents who met the criteria outlined in the target population section.
The 2014 SLCDC-MA sample was designed to produce reliable estimates at the national level by age group and sex. The targeted age groups were 18 to 34 years, 35 to 49 years, 50 to 64 years and 65 years and older (Table 2). As well, the sample allows for estimates at the regional level (Atlantic, Quebec, Ontario, Prairies, and British Columbia). The sample size was limited by the number of people who reported having been diagnosed with a mood and/or an anxiety disorder in the 2013 CCHS.

\section{Data collection and processing}

Statistics Canada collected data for the 2014 SLCDC-MA in two waves, each consisting of a five-week period: the first took place in November/December 2013, and the second in February/March 2014. Selected respondents were interviewed from centralized call centres using the CATI application.

Statistics Canada used several practices to minimize non-response. Introductory letters were sent to the targeted respondents explaining the purpose of the survey before the start of the collection period. Interviewers were instructed to make all reasonable attempts to obtain interviews; when a respondent was no longer available at the phone number provided on the 2013 CCHS, attempts were made to find their current number. For people who at first refused to participate, additional efforts were made, including a letter followed by a second call, in order to convince the respondent of the importance of their participation. Finally, to remove the possibility of language as a barrier, Statistics Canada was prepared to recruit interviewers with a wide range of language competencies if necessary. This was not required, however, as all interviews were conducted in either English (80\%) or French $(20 \%){ }^{36}$

Between April and September 2014, Statistics Canada processed, estimated, and documented the data. Editing, coding and the creation of derived and grouped variables were performed either at the interview stage (for editing and coding) or at the data processing stage (derived and grouped variables creation). A survey weight was given to each person on the final data file; the weight can be interpreted as the number of people in the population that are represented by the respondent. The 2014 SLCDC-MA weighting process began with the 2013 CCHS person-level share weight, because the 2014 SLCDC-MA survey frame was composed of respondents from this survey. A five-step weighting strategy was then used to adjust the sample weight for exclusions, sample selection, in-scope rates, non-response and permission to share and link.

Given the complex sampling design of the 2014 SLCDC-MA, the variance cannot be

TABLE 2

2014 SLCDC-MA initial sample size, modelled in-scope cases, and response rate by sex and age group

\begin{tabular}{lcccccc}
\hline \multicolumn{1}{|c}{ Sex } & $\begin{array}{c}\text { Age group } \\
\text { (years) }\end{array}$ & $\begin{array}{c}\text { Selected } \\
\text { sample } \\
\text { size }\end{array}$ & $\begin{array}{c}\text { Modelled } \\
\text { number of } \\
\text { in-scope cases }\end{array}$ & $\begin{array}{c}\text { Modelled } \\
\text { in-scope } \\
\text { rate }\end{array}$ & $\begin{array}{c}\text { Number of } \\
\text { respondents }\end{array}$ & $\begin{array}{c}\text { Response } \\
\text { rate }\end{array}$ \\
\hline Females & $18-34$ & 875 & 720 & $82.3 \%$ & 436 & $60.6 \%$ \\
& $35-49$ & 741 & 672 & $90.7 \%$ & 453 & $67.4 \%$ \\
\hline & $50-64$ & 1361 & 1211 & $89.0 \%$ & 892 & $73.7 \%$ \\
\hline Total & $65+$ & 990 & 765 & $77.3 \%$ & 559 & $73.1 \%$ \\
\hline Males & $18-34$ & 399 & 306 & $76.6 \%$ & 175 & $57.3 \%$ \\
\hline & $35-49$ & 425 & 350 & $82.4 \%$ & 226 & $64.5 \%$ \\
\hline & $50-64$ & 659 & 554 & $84.1 \%$ & 391 & $70.6 \%$ \\
\hline Total & $65+$ & 425 & 302 & $71.2 \%$ & 229 & $75.7 \%$ \\
\hline Overall & & 1908 & 1513 & $79.3 \%$ & 1021 & $67.5 \%$ \\
\hline
\end{tabular}

Abbreviation: SLCDC-MA, Survey on Living with Chronic Diseases in Canada-Mood and Anxiety Disorders Component. 
calculated using simple formulas and requires a resampling method. The bootstrap is an inference technique based on successive resampling. The survey bootstrap exploits the existing sample to build synthetic samples called "replicates." These replicates are used to estimate the variance of a parameter. Statistics Canada developed coordinated bootstrap weights for the 2014 SLCDC-MA because of its dependence on the 2013 CCHS sample. Hence, the starting point for the 2014 SLCDC-MA bootstrap weights was the 500 replicates from the 2013 CCHS share bootstrap file. Each bootstrap replicate was adjusted using the five adjustments steps listed previously. More information about the weighting process can be found in the 2013 CCHS User Guide. ${ }^{22}$

For respondents who agreed to share and link their responses, the 2014 SLCDC-MA data were linked to the 2013 CCHS.

\section{Data confidentiality and availability}

To preserve respondent confidentiality, all personal identifiers were removed from the share-linked file. Data were ready for use in October 2014 and were made available to PHAC, Health Canada and provincial health ministries. Researchers and third parties can access the 2014 SLCDC-MA data through university-based Research Data Centres run by Statistics Canada.

\section{Ethics}

Statistics Canada determined that ethics approval to administer the 2014 SLCDC-MA was not required as no physical measures were collected. No privacy or confidentiality risks, as governed by the Privacy Impact Assessment policy, were identified, and the Chief Statistician allowed the survey to proceed.

Respondents' participation in the 2014 SLCDC-MA was completely voluntary and proxy interviews were not permitted. Statistics Canada is prohibited by law from releasing any information it collects that could identify any person, business or organization, unless consent has been given by the respondent as per the Statistics Act. ${ }^{\dagger}$ Statistics Canada's share partners for the CCHS (i.e. PHAC, Heath Canada and provincial and territorial health departments) have access to the data under the terms of their respective data-sharing agreements. These data files contain information only on respondents who agreed to share their data with Statistics Canada's share partners and to link their responses from the 2014 SLCDC-MA to their responses from the 2013 CCHS. Personal identifiers were removed from the share files to respect respondent confidentiality. Users of these files must first certify that they will not at any time disclose information that might identify a survey respondent.

\section{Data quality}

\section{Out-of-scope cases}

Out-of-scope cases correspond to respondents approached to complete the survey but who should not be included because they do not meet the eligibility criteria for the survey.

The respondents of the 2014 SLCDC-MA were classified into two groups: resolved and unresolved cases. The unresolved case group consists of those respondents that could not be contacted during data collection, resulting in uncertainty about whether they belonged to the out-of-scope or in-scope category. The resolved case group consists of respondents that were selected in the sample and with whom Statistics Canada established contact and thus could determine whether they were out-of-scope or in-scope for the survey. Out-of-scope respondents included, for example, those who identified themselves as having a mood and/or an anxiety disorder in the 2013 CCHS but said they never had either disorder during the 2014 SLCDC-MA interview.

In order to minimize the number of outof-scope cases in the 2014 SLCDC-MA, two questions were included for follow-up with those respondents who reported that they do not currently have a mood or an anxiety disorder diagnosed by a health professional. These questions were aimed at identifying respondents who had ever been diagnosed with either type of disorder, but were no longer experiencing symptoms or who were able to manage their condition through medication or changes to their lifestyle. As a result, these respondents were included in the survey, which resulted in an overall reduction in the number of out-of-scope cases.

However, due to the number of out-ofscope cases, the total number of people who reported a mood and/or an anxiety disorder differs between the 2013 CCHS and the 2014 SLCDC-MA. The 2013 CCHS likely includes some respondents who reported having a mood and/or an anxiety disorder but do not (false positives). Conversely, the 2014 SLCDC-MA likely excluded some respondents who really do have the condition but who indicated otherwise to avoid completing the survey (false negatives). The extensive verifications performed through the Confirmation of Diagnosis module may have potentially contributed to increasing the validity of the 2014 SLCDC-MA diagnosis data, although this has not been empirically studied.

\section{Survey errors}

Generally, survey errors can be divided into sampling errors and non-sampling errors. Sampling errors occur because inferences about the entire population are based on information obtained from only a sample of that population, while nonsampling errors occur as a result of various systematic and random errors not attributed to sampling. ${ }^{22}$

\section{Sampling errors}

All 2013 CCHS respondents who reported a mood and/or an anxiety disorder were selected for the 2014 SLCDC-MA, after excluding respondents for operational reasons. However, because the 2013 CCHS is a sample survey, the 2014 SLCDC-MA is not a census of people with mood and/or anxiety disorders. It is an accepted fact that somewhat different estimates would be obtained if a census had been performed using the same questionnaire, interviewers, processing methods, etc.

\section{Non-sampling errors}

Non-sampling errors may occur at almost every step of a survey operation and can arise from problems in coverage, nonresponse, response and processing errors. ${ }^{21}$ Non-sampling errors cannot be quantified or mitigated by increasing the sample size.

Coverage errors occur when cases are omitted (under-coverage), duplicated or wrongfully included (over-coverage). The

${ }^{\dagger}$ An Act respecting statistics of Canada. Available from: http://laws-lois.justice.gc.ca/eng/acts/S-19 
2014 SLCDC-MA has the same coverage as the 2013 CCHS in the 10 provinces. Given the high coverage rate of the CCHS, it is unlikely that any significant bias was introduced into the 2014 SLCDC-MA data.

Non-response errors are the result of insufficient answers to the survey questions and can vary from partial nonresponse (i.e. failure to answer just one or several questions) to complete nonresponse. In the 2014 SLCDC-MA, people who partially responded to one or more questions were removed from the survey; however, as respondents tend to complete the questionnaire once they start the interview, partial non-response is rare. Complete non-response occurs because the interviewer is either unable to contact the respondent, or the respondent refuses to participate in the survey. In an effort to reduce the risk of being unable to follow up with selected respondents during the time period between the administration of the 2013 CCHS and the 2014 SLCDC-MA, the data collection was divided into two waves. Those who participated in the first six months of the 2013 CCHS data collection period were contacted as part of the first wave (November/December, 2013), while those in the latter six months of the 2013 CCHS data collection period comprised the second wave (February/March, 2014). The use of two waves ensured that the lag time between the 2013 CCHS and 2014 SLCDC-MA was no greater than 14 months. Complete non-response was addressed by adjusting the weight of individuals who responded to the survey to compensate for those who did not respond and to minimize any bias arising from non-response.

Response error may arise as a result of interviewers misunderstanding instructions, respondents making errors in answering questions or answers being incorrectly entered on the questionnaire. Statistics Canada implemented quality assurance measures in order to minimize these types of errors. These measures included the use of highly skilled interviewers, extensive training of interviewers with respect to the survey procedures and questionnaire, observation of interviews to ensure proper techniques and procedures were followed as well as to detect problems of questionnaire design or misunderstanding of instructions, and the use of procedures to ensure that data-capture errors were minimized. Finally, processing and tabulation errors were minimized by performing coding and quality checks to verify the processing logic.

\section{Data analysis}

We used descriptive analyses to characterize the survey respondents' sociodemographic characteristics. The analyses were carried out using SAS Enterprise Guide version 5.1 (SAS Institute, Cary, NC, USA). To account for sample allocation and survey design, all estimates were weighted using survey weights generated by Statistics Canada in order to reflect the age and sex distribution of the household population aged 18 or older in the 10 provinces. Furthermore, variance estimates ( $95 \%$ confidence intervals and coefficients of variation) were generated using the bootstrap weights provided with the data. ${ }^{37}$

The sociodemographic characteristics included in this analysis are

- $\quad$ sex (female; male);

- age (18-34; 35-49; 50-64; 65 + years);

- marital status (single; married or living common-law; widowed, separated, divorced);

- educational attainment (less than secondary school graduation; secondary school graduation, no post-secondary; some post-secondary education; postsecondary graduation);

- household income adequacy quintiles;

- immigrant status (yes; no);

- length of time in Canada since immigration ( $\leq 20$ years; > 20 years);

- Aboriginal status (yes; no);

- $\quad$ place of residence (urban; rural);

- geographical region (Atlantic; Quebec; Ontario; Prairies; British Columbia); and

- self-reported type of disorder diagnosed by a health professional (mood disorder only; anxiety disorder only; both mood and anxiety disorder).

Income was measured using the adjusted household income adequacy quintiles. Respondents were divided into quintiles based on the ratio of their total household income to the low income cut-off corresponding to their household and community size, as derived by Statistics Canada.
This measure provides, for each respondent, a relative measure of their household income to the household incomes of all other respondents. ${ }^{22}$ For respondents with missing income information, Statistics Canada uses nearest-neighbour donor imputation, which models income based on family structure, sociodemographics, some health variables, and income derived from aggregate tax information. Income was imputed for $23 \%$ of the 2014 SLCDC-MA respondents who did not provide a best estimate to the total household income question $(14.7 \%$ who fully reported income range; $4.1 \%$ who partially reported income range; and $4.7 \%$ who provided no income information).

\section{Results}

\section{Final 2014 SLCDC-MA sample}

The sample design of the 2014 SLCDC-MA is shown in Figure 1, and the initial sample size, modelled in-scope cases and response rate by sex and age group are summarized in Table 2 . A total of 7563 respondents who reported being diagnosed with a mood and/or an anxiety disorder by a health professional were captured in the sampling frame (2013 CCHS). Upon applying the predetermined exclusion criteria for the 2014 SLCDC-MA, 1688 respondents were excluded.

Of the 5875 respondents selected for the 2014 SLCDC-MA, 707 were found to be out-of-scope (resolved cases) which resulted in an out-of-scope rate of $17.0 \%$. An additional 287 were estimated to be out-ofscope based on predictions of logistic modelling (unresolved cases).

After excluding the out-of-scope respondents (resolved and unresolved), there were 4881 respondents within the modelled in-scope sample (i.e. respondents eligible for the 2014 SLCDC-MA interview), resulting in a modelled in-scope rate of $83.1 \%$.

Lastly, an additional 1520 respondents were excluded due to non-response (complete and partial), leaving a final sample of 3361 available for analysis. The overall response rate for the 2014 SLCDC-MA was therefore $68.9 \%$. The response rate was at its lowest among men (57.3\%) and women $(60.6 \%)$ from 18 to 34 years of age. 
FIGURE 1

2014 SLCDC-MA sample design

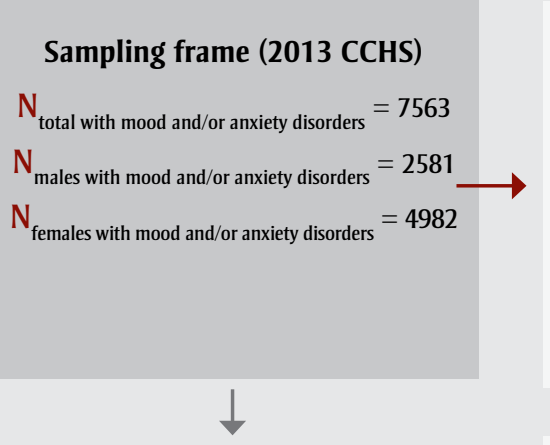

Sample selected

$n_{\text {total }}=5875$

$\mathrm{n}_{\text {males }}=1908$

$n_{\text {females }}=3967$

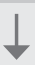

Modelled in-scope sample

$\mathrm{n}_{\text {total }}=4881$

$\mathrm{n}_{\text {males }}=1513$

$\mathrm{n}_{\text {females }}=3368$

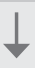

Final sample (2014 SLCDC-MA)

$$
\begin{gathered}
n_{\text {total }}=3361 \\
n_{\text {males }}=1021 \\
n_{\text {females }}=2340
\end{gathered}
$$

\section{Predetermined exclusions}

$\mathrm{n}_{\text {exclusions }}=1688$

Exclusion criteria:

- Being less than 18 years of age

- Being a resident of one of the three territories

- Not having a valid phone number

- Completing CCHS interview by proxy

- Not giving permission to share or link CCHS data

\section{Out-of-scope}

$\mathrm{n}_{\text {out-of-scope }}=994$ (707 resolved cases and 287 estimated for unresolved cases)

Reasons for being out-of-scope include:

- Being incorrectly classified as having the condition in the CCHS

- Deliberately providing answers in order to be screened out of the survey

- Emigrated

- Deceased

\section{Non-response}

$\mathrm{n}_{\text {non-response }}=1520$

Reasons for non-response include:

- Not having a valid phone number

- Not agreeing to participate

- Not completing the whole survey

- Not giving permission to share or link CCHS data

Abbreviations: CCHS, Canadian Community Health Survey; N, total population size; n, subsample size; SLCDC-MA, Survey on Living with Chronic Diseases in Canada-Mood and Anxiety Disorders Component.

\section{Sociodemographic characteristics of Canadians aged 18 years and older with mood and/or anxiety disorders}

The sociodemographic characteristics of the population with mood and/or anxiety disorders are presented in Tables 3 and 4 and Figure 2. Almost two-thirds (64\%) were female. While the highest proportion was aged 50 to 64 years, the proportion of young (18-34 years) and middle aged (35-64 years) were fairly evenly distributed. Seniors $(65+$ years $)$ represented only $15 \%$ of the population. More than half $(56 \%)$ were married or in a commonlaw relationship, approximately a quarter were single and the remaining $18 \%$ reported being separated, divorced or widowed. Close to two-thirds (60\%) reported having obtained a university degree, postsecondary certificate or diploma. Household income was fairly evenly distributed between the adequacy quintiles; however, individuals were more likely to report a household income within the lowest $(23 \%)$ versus highest $(17 \%)$ adequacy quintile. The majority $(88 \%)$ were Canadianborn, and two-thirds (67\%) of the immigrants had been living in Canada for more than 20 years. Most $(95 \%)$ were of nonAboriginal status and the majority (82\%) resided in an urban setting. The geographical distribution of the population was as follows: $40 \%$ resided in Ontario, $20 \%$ in Quebec, $17 \%$ in the Prairies, $14 \%$ in British Columbia and $9 \%$ in the Atlantic Provinces. Finally, 45\% reported being diagnosed by a health professional with a mood disorder only, $24 \%$ with an anxiety disorder only, and $31 \%$ reported having been diagnosed with both.

\section{Discussion}

The 2014 SLCDC-MA is the only population-based household survey to date that provides data on the experiences of Canadian adults with a professionally diagnosed mood and/or anxiety disorder. Topics covered by the survey include usual and work-related activities, stress, sleep, social relationships, clinical management strategies such as health professional contacts and recommendations, medication use, counselling and self-management practices. This survey addresses important data gaps identified by PHAC, the $\mathrm{MHCC}^{12}$ and other external stakeholder organizations.

Our findings with respect to the distribution of the sociodemographic characteristics among Canadian adults with mood and/or anxiety disorders generally agree with those from other studies. With respect to sex, mood and anxiety disorders have consistently been shown to be more common among females than males. ${ }^{38,39}$ Many factors may explain this, including behavioural (women have been shown to have more positive help-seeking attitudes than men), ${ }^{40}$ biological (hormonal fluctuations related to various aspects of reproductive function are thought to predispose women to depression), ${ }^{41}$ and sociocultural (women report experiencing stress related to work and family responsibilities more frequently than men). ${ }^{42}$

Studies carried out on populations with mood or anxiety disorders using a similar age range (18 years and older) have also shown that the age distribution of these disorders peaks in middle-age and declines in older age. ${ }^{38,39,43}$ The higher proportion of respondents in the middle-aged group may relate, in part, to the unique challenges that these individuals often face, such as stress associated with an imbalance between work and personal or family life. ${ }^{44,45}$ 
TABLE 3

Sociodemographic characteristics of Canadians aged 18 years and older with mood and/or anxiety disorders, 2014 SLCDC-MA

\begin{tabular}{|c|c|c|}
\hline \multirow[t]{2}{*}{ Sociodemographic characteristics } & \multicolumn{2}{|c|}{$\begin{array}{l}2014 \text { SLCDC-MA } \\
\quad(n=3361)\end{array}$} \\
\hline & $n^{\mathrm{a}}$ & $\%^{b}(95 \% \mathrm{Cl})$ \\
\hline \multicolumn{3}{|l|}{ Sex } \\
\hline Male & 1020 & $36.3(34.2-38.4)$ \\
\hline Female & 2341 & $63.7(61.6-65.8)$ \\
\hline \multicolumn{3}{|l|}{ Age (years) } \\
\hline $18-34$ & 610 & $26.0(24.0-28.1)$ \\
\hline $35-49$ & 682 & $27.9(25.6-30.3)$ \\
\hline $50-64$ & 1284 & $31.0(28.9-33.2)$ \\
\hline $65+$ & 785 & $15.0(13.8-16.2)$ \\
\hline \multicolumn{3}{|l|}{ Marital status } \\
\hline Single/never married & 823 & $26.3(23.8-28.7)$ \\
\hline Separated/divorced/widowed & 926 & $17.7(15.6-19.8)$ \\
\hline Married/common-law & 1610 & $56.1(53.2-58.9)$ \\
\hline \multicolumn{3}{|l|}{ Educational attainment } \\
\hline Less than secondary school graduation & 528 & $12.7(10.9-14.4)$ \\
\hline Secondary school graduation & 728 & $21.5(19.1-23.9)$ \\
\hline Some post-secondary education & 176 & $5.6 \quad(4.3-6.8)$ \\
\hline Post-secondary certificate, diploma or university degree & 1895 & $60.3(57.3-63.2)$ \\
\hline \multicolumn{3}{|l|}{ Household income adequacy quintiles } \\
\hline Q1 (lowest quintile) & 903 & $23.0(20.6-25.3)$ \\
\hline Q2 & 672 & $18.2(16.0-20.4)$ \\
\hline Q3 & 675 & $22.2(19.7-24.7)$ \\
\hline Q4 & 614 & $19.3(17.0-21.6)$ \\
\hline Q5 (highest quintile) & 497 & $17.3(15.0-19.7)$ \\
\hline \multicolumn{3}{|l|}{ Immigrant status } \\
\hline Yes & 283 & $12.5 \quad(9.9-15.1)$ \\
\hline No & 3074 & $87.5(84.9-90.1)$ \\
\hline \multicolumn{3}{|l|}{ Time in Canada since immigration } \\
\hline Less than or equal to 20 years & 61 & $33.5(22.7-44.3)$ \\
\hline More than 20 years & 222 & $66.5(55.7-77.3)$ \\
\hline \multicolumn{3}{|l|}{ Aboriginal status } \\
\hline Yes & 201 & $5.1 \quad(3.8-6.4)$ \\
\hline No & 2913 & $94.9(93.6-96.2)$ \\
\hline \multicolumn{3}{|l|}{ Place of residence } \\
\hline Rural & 873 & $17.7(15.8-19.6)$ \\
\hline Urban & 2488 & $82.3(80.4-84.2)$ \\
\hline \multicolumn{3}{|l|}{ Geographical region } \\
\hline Atlantic & 508 & $8.9 \quad(8.2-9.7)$ \\
\hline Quebec & 593 & $20.3(18.6-22.1)$ \\
\hline Ontario & 1162 & $39.8(37.7-42.0)$ \\
\hline Prairies & 690 & $17.2(15.6-18.8)$ \\
\hline British Columbia & 408 & $13.7(12.0-15.4)$ \\
\hline
\end{tabular}

Continued on the following page
Marital status is a key determinant of health and it is widely acknowledged that married individuals report better health outcomes and a lower risk for mortality than those who are not married, particularly men. ${ }^{46}$ Just over half of those in our study were married or in a common-law relationship, which is slightly higher than those found in other Canadians studies. $^{38,39}$ It is worth noting that these other studies further demonstrate that those with mood and anxiety disorders were less likely to be married or in a commonlaw relationship than those unaffected by these disorders.

Education is another important determinant of health and can have a significant influence on income level as well as economic well-being. ${ }^{47}$ The proportion of those with post-secondary education in our study was similar to the findings from other Canadian studies. ${ }^{38,39,48}$ All aforementioned studies found people with mood and anxiety disorders completed post-secondary education in the same proportion as those without these disorders. ${ }^{38,39}$ However, when broken down by type of post-secondary education attained, people with these disorders were less likely to have a post-secondary education at the Bachelor level or above than those who were not affected. ${ }^{48}$ With respect to income, while those in our study were more likely to report household income adequacy in the lowest quintile than in the highest, their household income adequacy was generally more evenly distributed between the quintiles compared to other studies..$^{38,39,48}$ Consequently, results based on data from the 2014 SLCDC-MA regarding health status, disorder-attributable impacts on usual and work-related activities and the management strategies adopted may reflect the best-case scenario, given the wealth of evidence that those of lower socioeconomic status are less healthy and less likely to adopt positive health behaviours. ${ }^{49}$

A slightly higher proportion of those in our study were of immigrant status than those found in other Canadian studies. ${ }^{38,39}$ These studies further demonstrated that those affected by mood and anxiety disorders were less likely to be immigrants than those unaffected, ${ }^{38,39}$ which may, in part, be explained by the "healthy immigrant effect," whereby foreign-born status presents a health advantage. ${ }^{50}$ Knowing 
TABLE 3 (continued)

Sociodemographic characteristics of Canadians aged 18 years and older with mood and/or anxiety disorders, 2014 SLCDC-MA

\begin{tabular}{|lrr|}
\hline \multicolumn{1}{|c}{ Sociodemographic characteristics } & \multicolumn{2}{c|}{$\begin{array}{c}\text { 2014 SLCDC-MA } \\
(\mathbf{n}=3361)\end{array}$} \\
\hline Type of disorder & 1531 & $45.2(42.2-48.2)$ \\
\hline \multicolumn{1}{|c|}{ Mood disorder only } & 770 & $24.0(21.5-26.6)$ \\
\hline \multicolumn{1}{|c|}{ Anxiety disorder only } & 1060 & $30.7(28.0-33.4)$ \\
\hline Mood and anxiety disorder
\end{tabular}

Abbreviations: Cl, confidence interval; Q, quintile; SLCDC-MA, Survey on Living with Chronic Diseases in Canada-Mood and Anxiety Disorders Component.

${ }^{a}$ Numbers are unweighted.

${ }^{\mathrm{b}}$ Percentages are based on weighted numbers to reflect the Canadian population aged 18 years and older with mood and/or anxiety disorders living in the 10 provinces.

that this health advantage lessens with the length of time lived in Canada, ${ }^{50}$ it is important to note that a large proportion $(66.5 \%)$ of those who reported being an immigrant in our study had lived in Canada for more than 20 years.

The proportion of those living in a rural area and the proportion who reported to be of Aboriginal descent in our study were comparable to other Canadian studies. ${ }^{38,39}$ Neither these studies nor ours demonstrated a difference between those with and those without mood and anxiety disorders in terms of the proportion living in a rural area or having Aboriginal status. ${ }^{38,39}$ Given that Aboriginal peoples are known to be at greater risk for mental illness, ${ }^{51,52}$ and that those living in the territories and persons living on reserves or Crown lands were not included in these studies nor ours, these findings could be a reflection of the underrepresentation of
Aboriginal peoples in the population sampled.

Finally, a third of those in our study reported having been diagnosed with both mood and anxiety disorders. Epidemiological studies from Europe and the United States have shown consistently high comorbidity rates for current and lifetime depressive and anxiety disorders, ranging from $44 \%$ to $81 \%{ }^{6-9}$ Differences in the sampling frame and/or diagnostic criteria used may account for differences in study results. Furthermore, it has been shown that individuals with co-occurring mental health issues tend to demonstrate significantly greater impacts on health and use of mental health services. ${ }^{38,53,54}$ Since differences between those with comorbid disorders and those with one disorder only may emerge in terms of respondents' health status, disorder-attributable impacts on usual and work-related activities and management or self-management practices, consideration should be given to stratifying the survey data by disorder type.

\section{Strengths and limitations}

The 2014 SLCDC-MA provides detailed information on a wide variety of topics related to the experiences of Canadians living with mood and/or anxiety disorders, which is not feasible in a general population-based health survey. Furthermore, responses are linked to those from the source survey (the 2013 CCHS), creating an even richer dataset because the CCHS collects additional health-related information on topics such as comorbidities, lifestyle behaviours and health determinants. Associations between different factors can be explored; however, causal inferences cannot be drawn from the results due to the survey's cross-sectional design. ${ }^{55}$

While the 2014 SLCDC-MA was developed to be nationally representative, the generalizability of the data to the entire Canadian population may be restricted due to the exclusion of the territories and some populations known to be at risk for mental illness, such as Aboriginal peoples $^{51,52}$ living on reserves or Crown lands, the homeless, ${ }^{56}$ institutionalized patients, ${ }^{57}$ and prison residents. ${ }^{58}$ The study sample is also limited to Canadians who sought care and received a mood and/or an anxiety disorder diagnosis. Hence, the generalizability of the results to those who do not seek care but meet diagnostic criteria for a

\section{TABLE 4}

Type of disorder by sex and age among Canadians aged 18 years and older with mood and/or anxiety disorders, 2014 SLCDC-MA

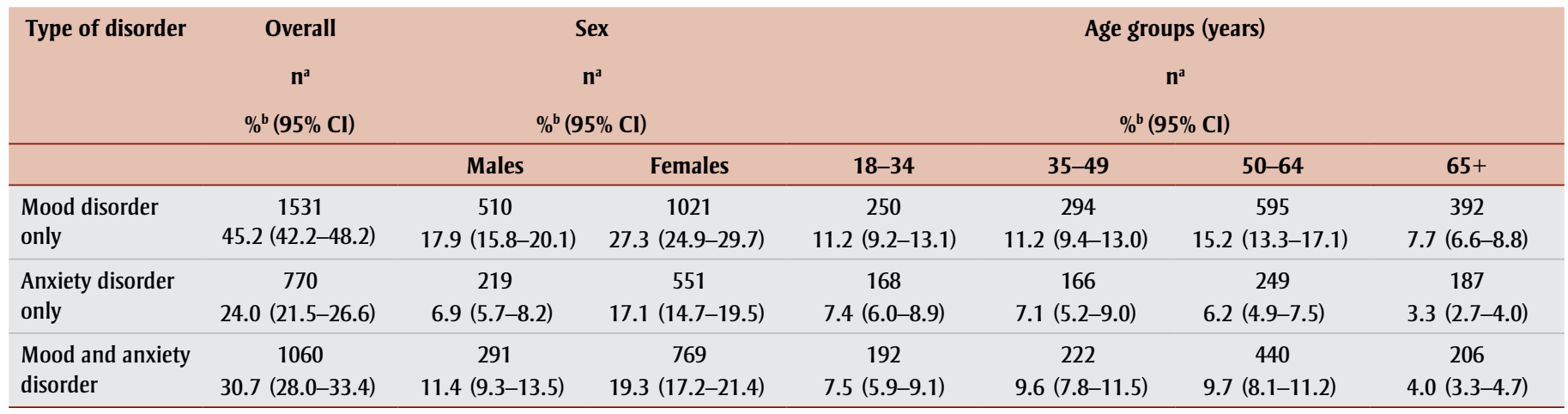

Abbreviations: Cl, confidence interval; SLCDC-MA, Survey on Living with Chronic Diseases in Canada-Mood and Anxiety Disorders Component

${ }^{a}$ Numbers are unweighted.

${ }^{\mathrm{b}}$ Percentages are based on weighted numbers to reflect the Canadian population aged 18 years and older with mood and/or anxiety disorders living in the 10 provinces. 
FIGURE 2

Distribution of Canadians aged 18 years and older with mood and/or anxiety disorders by (a) marital status, (b) educational attainment, (c) household income adequacy quintiles, (d) geographical region, (e) type of disorder by sex and (f) type of disorder by age groups, 2014 SLCDC-MA
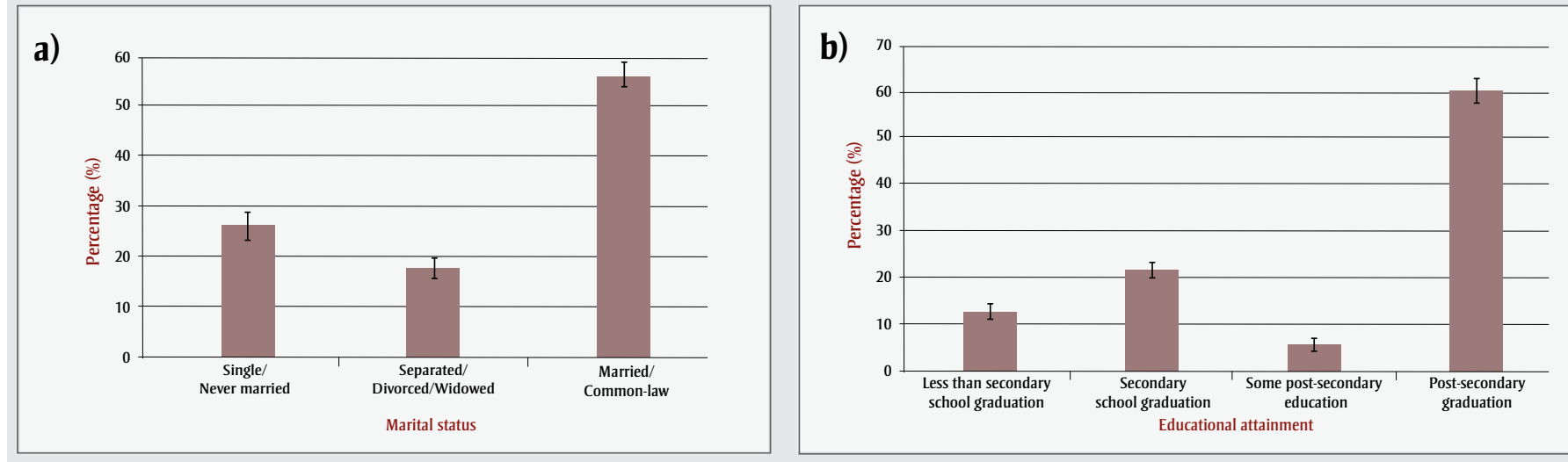

c)

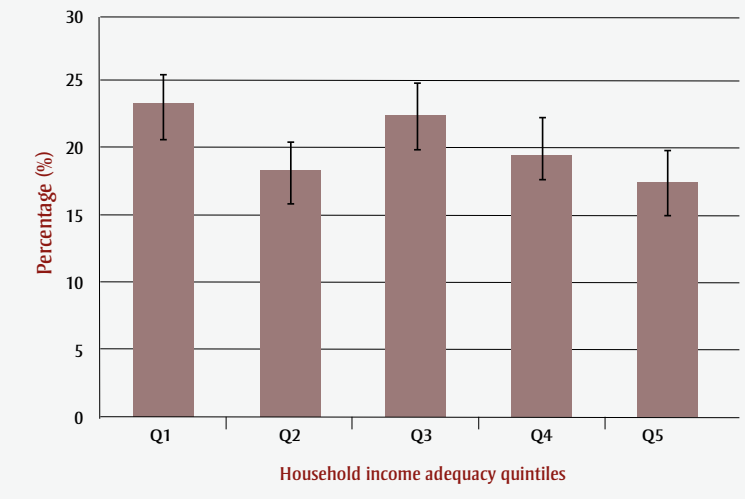

d)

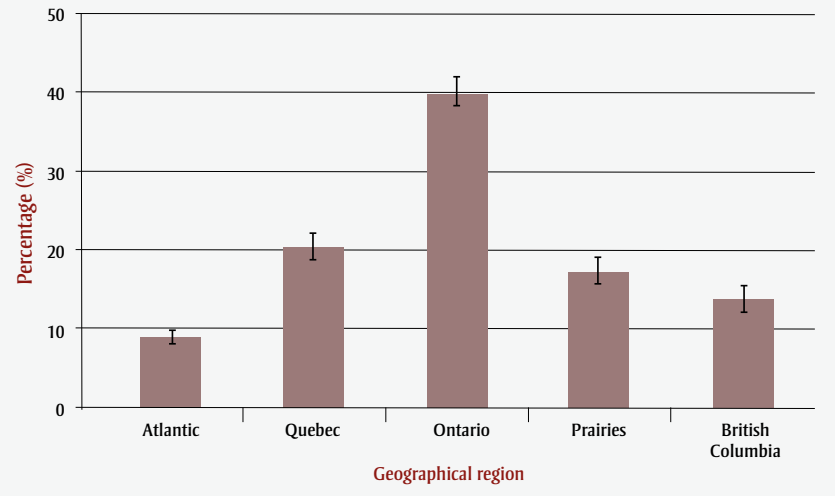

e)

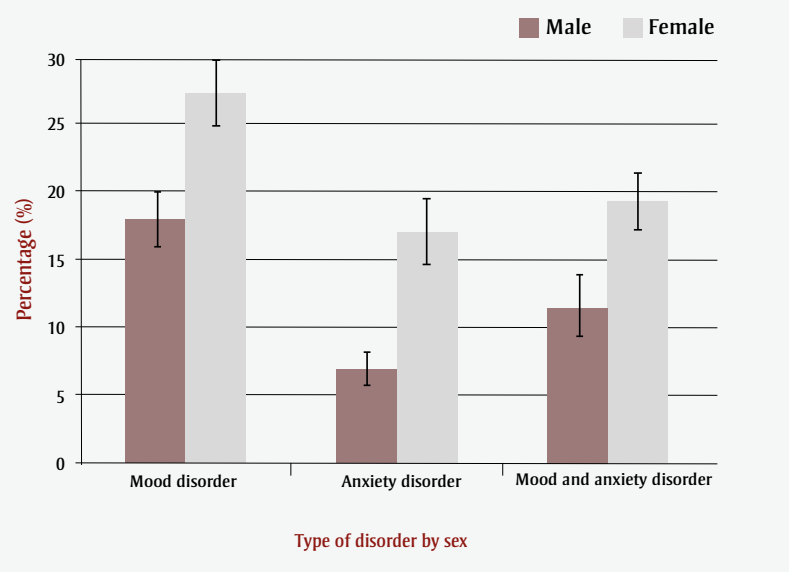

f)
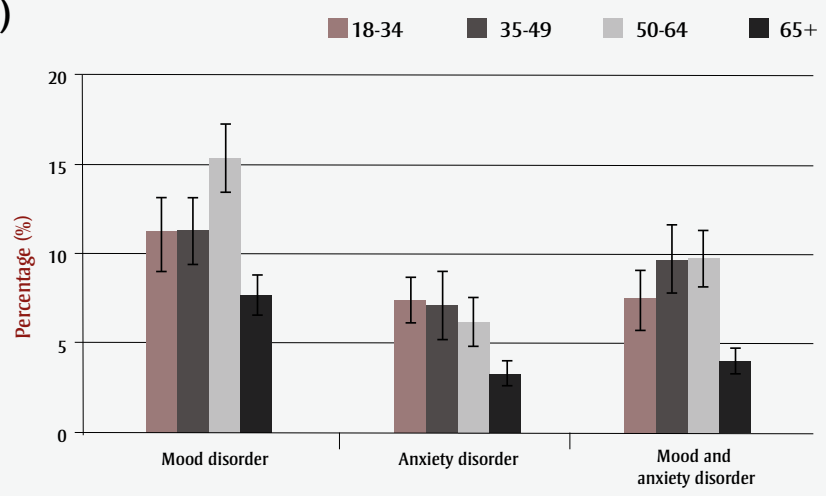

Type of disorder by age groups (years)

Abbreviation: SLCDC-MA, Survey on Living with Chronic Diseases in Canada-Mood and Anxiety Disorders Component.

Note: Percentages are based on weighted numbers to reflect the Canadian population aged 18 years and older with mood and/or anxiety disorders living in the 10 provinces; error bars represent $95 \%$ confidence intervals.

mood and/or an anxiety disorder is uncertain.

As with most population-based health surveys, the 2014 SLCDC-MA relies on self-reporting of mental disorders and health-related practices or events with no third-party corroboration or verification of these self-reports. While it is the most practical method of assessing disease status and its impact in large population studies, self-reporting of health events is susceptible to misclassification due to social desirability bias, recall bias and conscious non-reporting, resulting in potential under- or overestimation of disease burden, both individual and societal. Research has found acceptable to good 
agreement between self-reported physical health conditions and diagnoses made by medical professionals, ${ }^{59}$ but validation of the questions used in the CCHS to ascertain self-reported mood and anxiety disorders has not yet, to our knowledge, been examined.

During the data collection period of the 2013 CCHS, the Diagnostic and Statistical Manual of Mental Disorders, Fifth Edition $(D S M-V)^{60}$ was released. However, given that data collection was well underway during the transition from the Diagnostic and Statistical Manual of Mental Disorders, Fourth Edition-Text Revision $(D S M-I V-T R)^{61}$ to the DSM-V, the mood and anxiety disorders as defined within the DSM-IV-TR are reflected in the case finding questions in the 2013 CCHS.

Analytical limitations due to available sample size should be anticipated when disaggregating data by age, sex (especially males), geography or other characteristics of interest. For example, it was not possible to provide a statistical description of the population by ethnic group, as the estimates for the different categories had high coefficients of variation $(\mathrm{CV})$, indicating high sampling variability and estimates of unacceptable quality. Consideration was given to collapsing Black, Arab and Asian ethnic groups into a "non-White" category; however, this resulted in a very diverse group, a persistently high sampling variability $(\mathrm{CV}=22 \%)$ and a potentially limited or non-meaningful interpretation of the results.

Finally, the 2014 SLCDC-MA response rate (68.9\%) was lower relative to previous SLCDC cycles (75\% to $83.2 \%$ ). ${ }^{62,63}$ There is a well-documented general decline in response rates for surveys both in Canada and around the world, and the 2014 SLCDC-MA's response rate follows the same pattern as other general and healthrelated surveys. ${ }^{64}$ Since non-responders did not agree to share their information with Statistics Canada's share partners, which includes PHAC, their sociodemographic characteristics and the reasons for not participating in the survey are unknown.

\section{Conclusion}

Mood and anxiety disorders are the most common mental disorders in Canada and have a major impact on the daily lives of those affected by them. ${ }^{1}$ At present, the
2014 SLCDC-MA, a cross-sectional followup survey to the 2013 CCHS, is the only Canadian population-based household survey reporting information on the impact of these disorders on usual and work-related activities, and the strategies used to manage them. The survey data can offer insights to public health practitioners and clinicians about areas where additional support or intervention may be needed, and can provide baseline information for future public health research in the field of mental illness.

\section{Acknowledgements}

The 2014 SLCDC-MA was funded by PHAC and developed in conjunction with Statistics Canada. This survey was developed through the contribution of time and expertise from members of PHAC's Mental Health and Mental Illness Advisory Committee. The 2013 CCHS was conducted by Statistics Canada in partnership with Health Canada and PHAC, with funding from the Canadian federal government. No external financial or material support was obtained for this study.

\section{Conflict of interest}

The authors declare no conflict of interest.

\section{References}

1. Pearson C, Janz T, Ali J. Mental and substance use disorders in Canada. Statistics Canada: Health at a Glance [Internet]. 2013 Sept 18 [updated 2015 Nov 27; cited 2016 June 24]. Available from: http://www.statcan .gc.ca/pub/82-624-x/2013001/article /11855-eng.htm

2. Public Health Agency of Canada. Mood and Anxiety Disorders: Fast Facts from the 2014 Survey on Living with Chronic Diseases in Canada [Internet]. Ottawa (ON): Government of Canada; 2015 June 3 [cited 2016 Jun 24]. Available from: http://www .healthycanadians.gc.ca/publications /diseases-conditions-maladies-affections /mental-mood-anxiety-anxieux-humeur /index-eng.php

3. Government of Canada. The Human Face of Mental Health and Mental Illness in Canada. Ottawa (ON): Minister of Public Works and Government Services Canada; 2006 [Catalogue no.: HP5-19/2006E].
4. Devane CL, Chiao E, Franklin M, Kruep EJ. Anxiety disorders in the 21st century: status, challenges, opportunities, and comorbidity with depression. Am J Manag Care. 2005; 11 (Suppl 12):S344-53.

5. Lenze EJ, Mulsant BH, Shear MK, et al. Comorbid anxiety disorders in depressed elderly patients. Am J Psychiatry. 2000;157(5):722-8.

6. Lamers F, van Oppen P, Comijs HC, et al. Comorbidity patterns of anxiety and depressive disorders in a large cohort study: the Netherlands Study of Depression and Anxiety (NESDA). J Clin Psychiatry. 2011 Mar;72(3): 341-8.

7. de Graaf R, Bijl RV, Spijker J, Beekman AT, Vollebergh WA. Temporal sequencing of lifetime mood disorders in relation to comorbid anxiety and substance use disorders--findings from the Netherlands Mental Health Survey and Incidence Study. Soc Psychiatry Psychiatr Epidemiol. 2003 Jan;38(1):1-11.

8. Brown TA, Campbell LA, Lehman CL, Grisham JR, Mancill RB. Current and lifetime comorbidity of the DSM-IV anxiety and mood disorders in a large clinical sample. J Abnorm Psychol. 2001 Nov;110(4):585-99.

9. Kessler RC, Berglund P, Demler O, et al. National Comorbidity Survey Replication. The epidemiology of major depressive disorder: results from the National Comorbidity Survey Replication (NCS-R). JAMA. 2003; 289(23):3095-105.

10. Strine TW, Mokdad AH, Balluz LS, et al. Depression and anxiety in the United States: findings from the 2006 Behavioral Risk Factor Surveillance System. Psychiatr Serv 2008;59: 1383-90.

11. Kessler RC, Adler L, Barkley R, et al. The prevalence and correlates of adult ADHD in the United States: results from the National Comorbidity Survey Replication. Am J Psychiatry 2006;163(4):716-23.

12. Mental Health Commission of Canada. Changing directions, changing lives: the mental health strategy for Canada. Calgary (AB): Mental Health Commission of Canada; 2012. 
13. Anderson IM, Haddad PM. CANMAT guidelines for depression: clear and user-friendly. J Affect Disord. 2009; 117(Suppl 1):S3-4.

14. Starkes JM, Poulin CC, Kisely SR. Unmet need for the treatment of depression in Atlantic Canada. Can J Psychiatry. 2005;50(10):580-90.

15. Kasper S. Anxiety disorders: underdiagnosed and insufficiently treated. Int J Psychiatry Clin Pract. 2006;10 (Suppl 1):3-9.

16. Kohn R, Saxena S, Levav I, Saraceno $B$. The treatment gap in mental health care. Bull World Health Organ. 2004;82(11):858-66.

17. Weisberg RB, Dyck I, Culpepper L, Keller MB. Psychiatric treatment in primary care patients with anxiety disorders: a comparison of care received from primary care providers and psychiatrists. Am J Psychiatry. 2007;164(2): 276-82.

18. Issakidis C, Andrews G. Service utilisation for anxiety in an Australian community sample. Soc Psychiatry Psychiatr Epidemiol. 2002;37(4):153-63.

19. Thompson A, Hunt C, Issakidis C. Why wait? Reasons for delay and prompts to seek help for mental health problems in an Australian clinical sample. Soc Psychiatry Psychiatr Epidemiol. 2004;39(10):810-17.

20. Statistics Canada. 2014 Survey on Living with Chronic Diseases in Canada-Mood and Anxiety Disorders Component [Internet]. Ottawa (ON): Government of Canada; 2013 Oct 18 [cited 2016 Jun 24]. Available from: http://www23.statcan.gc.ca/imdb $/$ p2SV.pl?Function = getSurvey\&SDDS $=5160$

21. Statistics Canada. Survey on Living with Chronic Diseases in Canada: user guide. Ottawa (ON): Statistics Canada; 2014.

22. Statistics Canada. Canadian Community Health Survey (CCHS)-Annual Component: user guide 2013 microdata files. Ottawa (ON): Statistics Canada; 2014.

23. Statistics Canada. 2013 Canadian Community Health Survey (CCHS)Annual Component: questionnaire. Ottawa (ON): Statistics Canada; 2014.
24. Statistics Canada. 2009 Survey on Living with Chronic Diseases in Canada (SLCDC)-Arthritis Component: questionnaire. Ottawa (ON): Statistics Canada; 2009.

25. Statistics Canada. 2011 Survey on Living with Chronic Diseases in Canada (SLCDC)-Respiratory Component: questionnaire. Ottawa (ON): Statistics Canada; 2011.

26. Statistics Canada. 2011 Survey on Living with Chronic Diseases in Canada (SLCDC)-Diabetes Component: questionnaire. Ottawa (ON): Statistics Canada; 2011.

27. Statistics Canada. 2009 Survey on Living with Chronic Diseases in Canada (SLCDC)-Hypertension Component: questionnaire. Ottawa (ON): Statistics Canada; 2009.

28. Katzman MA, Bleau P, Blier P, et al. Canadian clinical practice guidelines for the management of anxiety, posttraumatic stress and obsessive-compulsive disorders. BMC Psychiatry. 2014;14(Suppl 1):S1. Available from: http://www.biomedcentral.com /content/pdf/1471-244X-14-S1-S1.pdf

29. Kennedy SH, Lam RW, Parikh SV, Patten SB, Ravindran AV. Canadian Network for Mood and Anxiety Treatments (CANMAT) clinical guidelines for the management of major depressive disorder in adults. J Affect Disord. 2009 Oct;117(Suppl 1): S1-S2. Available from: http://www.canmat .org/resources / C A N MAT \% 20 Depression \% 20Guidelines \% 202009 .pdf

30. Adams PF, Kirzinger WK, Martinez ME. Summary health statistics for the U.S. population: National Health Interview Survey, 2012. Vital Health Stat 10. 2013;(259):1-95.

31. Cutrona CE, Russell DW. The provisions of social support and adaptation to stress. Advances Personal Relation. 1987;1, 37-67.

32. Caron J. L'Échelle de provisions sociales : une validation québécoise. Sante Ment Que. 1996 Autumn; 21(2):158-80.

33. Caron J. Une validation de la forme abrégée de l'Échelle de provisions sociales : l'ÉPS-10 items. Sante Ment Que. 2013 Spring;38(1):297-318.
34. Collins, D. Pretesting survey instruments: an overview of cognitive methods. Qual Life Res. 2003;12(3): 229-38.

35. Presser S, Couper MP, Lessler JT, et al. Methods for testing and evaluating survey questions. Public Opin Q. 2004; 68(1):109-30.

36. Statistics Canada. Survey on Living with Chronic Diseases in Canada: data dictionary. Ottawa (ON): Statistics Canada; 2014.

37. Rust K, Rao JN. Variance estimation for complex surveys using replication techniques. Stats Methods Med Res. 1996;5:281-310.

38. Pelletier L, O’Donnell S, McRae L, Grenier J. The burden of generalized anxiety disorders in Canada. Health Promot Chronic Dis Prev Can. Forthcoming 2017.

39. Pelletier L, O’Donnell S, Dykxhoorn J, McRae L, Patten SB. Under-diagnosis of mood disorders in Canada. Epidemiol Psychiatr Sci. 2016 May 6:1-10. [Epub ahead of print.]

40. Kazanjian A, Morettin D, Cho R. Health care utilization by Canadian women. BMC Womens Health. 2004; 4(Suppl 1):S33.

41. Noble RE. Depression in women. Metabolism. 2005 May;54(5 Suppl 1):49-52.

42. Duxbury L, Higgins C, Lee C. Workfamily conflict: a comparison by gender, family type, and perceived control. J Fam Issues. 1994 Sept;15(3): 449-66.

43. Hobbs MJ, Anderson TM, Slade T, Andrews G. Relationship between measurement invariance and age-related differences in the prevalence of generalized anxiety disorder. J Affect Disord. 2014;152-154: 306-12.

44. Siegrist J. Chronic psychosocial stress at work and risk of depression: evidence from prospective studies. Eur Arch Psychiatry Clin Neurosci. 2008 Nov;258 Suppl 5:115-9.

45. Wang JL, Lesage A, Schmitz N, Drapeau A. The relationship between work stress and mental disorders in men and women: findings from a population-based study. J Epidemiol Community Health. 2008 Jan;62(1): 42-7. 
46. Robards J, Evandrou M, Falkingham J, Vlachantoni A. Marital status, health and mortality. Maturitas. 2012;73(4):295-9. doi: 10.1016/j. maturitas.2012.08.007. [Epub 2012 Sep 21.]

47. Frank JW, Mustard JF. The determinants of health from a historical perspective. Daedalus. 1994;123(4):1-17.

48. Diotte E. Mental health and equality rights: mood disorders-an analysis using the 2012 Canadian Community Health Survey (CCHS)-Mental Health Component. Ottawa (ON): Canadian Human Rights Commission; 2015. 19 p. [Catalogue No.: HR4-28/2015E-PDF.]

49. Pampel FC, Krueger PM, Denney JT. Socioeconomic disparities in health behaviors. Annu Rev Sociol. 2010 Aug;36:349-370.

50. Vang Z; Sigouin J, Flenon A, Gagnon A. The healthy immigrant effect in Canada: a systematic review. Population Change and Lifecourse Strategic Knowledge Cluster Discussion Paper Series. 2015;3(1):Article 4. Available from: http://ir.lib.uwo.ca /pclc/vol3/iss1/4

51. MacMillan HL, Jamieson E, Walsh $\mathrm{CA}$, et al. First Nations women's mental health: results from an Ontario survey. Arch Women Ment Health. 2008;11(2):109-15.

52. Government of Canada. The mental health and well-being of Aboriginal peoples in Canada. In: The human face of mental health and mental illness in Canada 2006. Ottawa (ON): Government of Canada; 2006:159-79. [Catalogue No.: HP5-19/2006E].

53. Kessler RC, McGonagle KA, Zhao S, et al. Lifetime and 12-month prevalence of DSM-III-R psychiatric disorders in the United States. Results from the National Comorbidity Survey. Arch Gen Psychiatry. 1994 Jan;51(1):8-19.

54. McLaughlin TP, Khandker RK, Kruzikas DT, Tummala R. Overlap of anxiety and depression in a managed care population: prevalence and association with resource utilization. J Clin Psychiatry. 2006 Aug;67(8): 1187-93.
55. Bland M. An introduction to medical statistics. 3rd ed. Oxford: Oxford University Press; 2001.

56. Krausz RM, Clarkson AF, Strehlau V, Torchalla I, Li K, Schuetz CG. Mental disorder, service use, and barriers to care among 500 homeless people in 3 different urban settings. Soc Psychiatry Psychiatr Epidemiol 2013 Aug;48(8):1235-43.

57. Seitz D, Purandare N, Conn D. Prevalence of psychiatric disorders among older adults in long-term care homes: a systematic review. Int Psychogeriatr 2010 Nov;22(7):1025-39.

58. Simpson AI, McMaster JJ, Cohen SN Challenges for Canada in meeting the needs of persons with serious mental illness in prison. J Am Acad Psychiatry Law. 2013;41(4):501-9.

59. Kriegsman DM, Penninx BW, van Eijk JT, Boeke AJ, Deeg DJ. Self-reports and general practitioner information on the presence of chronic diseases in community dwelling elderly. A study on the accuracy of patients' self-reports and on determinants of inaccuracy. J Clin Epidemiol. 1996;49(12): 1407-17.

60. American Psychiatric Association. Diagnostic and statistical manual of mental disorders. 5th ed. Washington (DC): American Psychiatric Association; 2013.

61. American Psychiatric Association. Diagnostic and statistical manual of mental disorders. 4th ed., text revision. Washington, DC: American Psychiatric Association; 2000.

62. Statistics Canada. Survey on Living with Chronic Diseases in Canada user guide - December 2009 [Internet]. 2010 Jan [cited 2016 Jun 24]. Available from: www.statcan.gc.ca/imdb-bmdi /document/5160_D5_T1_V1-eng .html\#a11

63. Statistics Canada. Survey on Living with Chronic Diseases in Canada user guide - November 2011 [Internet]. 2011 Nov [cited 2016 Jun 24]. Available from: http://www23.statcan.gc.ca /imdb-bmdi/document/5160_D4_T1 _V2-eng.htm
64. Bladon TL. The downward trend of survey response rates: implications and considerations for evaluators. Canadian J Prog Eval [Internet]. 2009 Spring [cited 2016 Jun 24];24(2):13156. Available from: http://www .evaluationcanada.ca/s ecure /24-2-131.pdf 